\title{
30 ANOS DE EJA NA UFMG - Extensão, Formação e Pesquisa
}

Leôncio Soares ${ }^{(*)}$

Nos últimos trinta anos, registramos vários avanços no campo da Educação de Jovens e Adultos no Brasil: ampliaram-se as modalidades de oferta, diversificaram-se as ações em torno da formação inicial e continuada dos professores que atuam junto a esses sujeitos, multiplicaram-se as pesquisas e publicações sobre o tema e aos adultos foi reconhecido o direito legal à educação.

Essa não era, entretanto, a situação observada em meados dos anos de 1980. O país vivia o momento da redemocratização e o direito dos jovens e adultos à educação só viria a ser conquistado com a Constituição Federal de 1988, que estabelecia o direito de todos à educação, independentemente da idade. ${ }^{1}$ Regida pela LDB 5.692/71, a educação de adultos, no que se refere às ações de escolarização, recebia o tratamento de ensino supletivo, ${ }^{2}$ que tinha como principal característica a oferta de um ensino compensatório e aligeirado. Com taxas elevadas de analfabetismo $(18,4 \%)$ e de baixa escolarização da população com 15 anos ou mais $(3,03$ anos de estudo), a oferta do ensino supletivo se dava predominantemente pelas ações dos governos estaduais via cursos e exames.

Foi nesse contexto que o Centro Pedagógico da Universidade Federal de Minas Gerais criou um projeto de extensão, denominado Curso Supletivo, para atender inicialmente aos funcionários que trabalhavam na Universidade e não haviam concluído o então denominado primeiro grau. Ao mesmo tempo, foi criada a habilitação em Educação de Adultos no Curso de Pedagogia para oferecer uma preparação apropriada àqueles que desejassem trabalhar com esse público. Nessa mesma direção, iniciou-se uma linha de pesquisa no Programa de Pós-graduação para desenvolver investigações no campo da educação de adultos.

\footnotetext{
${ }^{(*)}$ Possui doutorado em Educação pela Universidade de São Paulo (1995). Esteve como Professor visitante na Universidade Federal de Pernambuco em 2002-2003. Realizou pós-doutoramento na Universidade Federal Fluminense em 2006, com bolsa do CNPq. É professor associado da Universidade Federal de Minas Gerais. Pesquisa e publica na área de Educação, com ênfase em Educação de Jovens e Adultos, abordando a política educacional, a formação docente, a escolarização de jovens e adultos e a história da educação. Realizou de 2012 a 2013, pós-doutoramento na Northern Illinois University, em Illinois, Estados Unidos da América, com bolsa da CAPES. Currículo: <http://buscatextual.cnpq.br/buscatextual/visualizacv.do?id=K4769382A4>.

${ }^{1}$ Para uma análise da educação de adultos como direito, ver, entre outros, HADDAD, S.; PIERRO, Maria Clara Di . Escolarização de jovens e adultos. Revista Brasileira de Educação, São Paulo, v. no 14, maio-agosto, p. 108-130, 2000.

${ }^{2}$ Para uma análise sobre o ensino supletivo no período, ver HADDAD, S. Estado e Educação de Adultos (1964-85). Mestrado. Universidade de São Paulo, USP, Brasil. 1982.
} 
Este artigo descreve e analisa esse conjunto de ações que, a partir desse momento, passou a ser desenvolvida na UFMG, envolvendo simultaneamente a extensão, a formação e a pesquisa voltadas para a educação de jovens e adultos.

\section{PROJETO DE EXTENSÃO COMO ESPAÇO DE ACOLHIMENTO E SOCIALIZAÇÃO DO PÚBLICO JOVEM E ADULTO}

Atividades de educação voltadas para jovens, adultos e idosos existem desde há muito tempo por iniciativa comunitária, de grupos de igrejas, de sindicatos, de movimentos sociais e de serviços dos órgãos ligados à iniciativa empresarial como o SESC e o SESI e, eventualmente, de municípios e províncias/estados (SOARES, GALVÃO, 2005). Entretanto, é principalmente a partir da Primeira Campanha Nacional de Educação de Adultos em 1947, realizada pelo Ministério da Educação e Saúde, que passamos a ter uma política governamental, ou seja, uma ação sistemática de atendimento público a essa população. ${ }^{3}$

Nas décadas de 1970 e 1980, o que existiu oficialmente foi o Mobral (1969/1984) para os que ainda não tinham se alfabetizados e o ensino supletivo ${ }^{4}$ (1972/1996), ofertado pelos estados, para os que interromperam os estudos. Havia, ainda, ampla cobertura dos cursinhos particulares. Nesse período, o envolvimento das instituições de ensino superior, quando acontecia, era na criação de projetos de extensão. ${ }^{5}$ No entanto, como a educação para esse público não era reconhecida como direito, a formação, bem como a oferta da EJA seguia sem serem assumidas como política pública. Beisiegel (1997) denunciou por muito tempo a desobrigação do Estado para com o atendimento à educação daqueles em condição de analfabetismo ou mesmo com pouca escolaridade.

Foi nesse contexto que, em 1985, a Associação dos Servidores da UFMG reivindicou, junto à reitoria, a oferta de curso de ensino fundamental para os trabalhadores. Paralelamente, um grupo de professores do Centro Pedagógico - Escola de Ensino Fundamental da UFMG -, discutia a possibilidade de ser criado naquele espaço ocioso do período noturno, um curso para adultos para

\footnotetext{
${ }^{3}$ Para uma análise dessa Campanha, ver PAIVA, V. História da Educação Popular no Brasil. Educação Popular e Educação de Adultos. São Paulo, Loyola, 2003.

${ }^{4}$ Para maior aprofundamento do que se estabeleceu como concepção de educação de adultos no período, ler Parecer 699/72, do CFE, do Conselheiro Valnir Chagas intitulado A Doutrina do Ensino Supletivo.

${ }^{5}$ É desse período o surgimento de projetos de extensão de educação de adultos nas universidades públicas brasileiras. Destacamos aqui os projetos na UFES, na UFSCAR, na UFPB, na UnB, na UFRGS e na UFMG. Para um entendimento mais aprofundado sobre a entrada da educação de adultos nas universidades por meio dos projetos de extensão consultar Carlos Fabian de Carvalho. A educação de jovens e adultos e universidade: a experiência do núcleo de educação de jovens e adultos da Universidade Federal do Espírito Santo. 2004. Dissertação (Mestrado em Educação) - Universidade Federal de Minas Gerais.
} 
atender à parcela da população que não teve acesso a escolarização básica. Naquele momento, começava na UFMG uma reflexão a respeito do enorme contingente da população que não havia conseguido completar o ensino fundamental. As discussões giravam em torno das seguintes questões: quais os motivos que levava parte significativa da população a sair da escola? Por que desejava voltar a estudar? Dessas reflexões, surgiu o Projeto de Extensão de Educação de Adultos, com duração de dois anos, com os seguintes objetivos: atendimento aos servidores da universidade com o ensino fundamental incompleto, realização de pesquisas no campo da educação de adultos e formação de educadores (SOARES, 1997).

A criação do Projeto de Educação de Adultos na universidade possibilitou o desenvolvimento de práticas mais autônomas se comparadas às desenvolvidas no âmbito da rede pública e privada naquele período. Para contextualizar o tratamento limitado dado ao atendimento à educação de adultos no estado de Minas Gerais, a legislação da época restringia a aprovação e a certificação dos estudantes aos Centros de Estudos Supletivos ${ }^{6}$ e a apenas duas escolas privadas existentes no estado. Portanto, o fato do Projeto de Extensão da UFMG conquistar o direito à avaliação no processo e, consequentemente, a certificação possibilitou a formulação de um currículo mais interdisciplinar, sem as amarras impostas por avaliações externas.

A presença do público jovem e adulto, com toda a diversidade que caracteriza essa população, trouxe novas questões para serem respondidas pelos coordenadores, professores e licenciandos do Projeto. Por serem concebidos como sujeitos de direitos, uma das primeiras questões foi propor uma solução para o ingresso dos jovens e adultos no Projeto. Inicialmente, muitos professores tinham dificuldade em propor um outro formato que não fosse a realização de provas. Durante os dois primeiros semestres, elaboramos coletivamente provas que foram aplicadas no decorrer da primeira semana de aula. Se fazer prova não representava problema para aqueles que haviam deixado a escola recentemente, para os demais significava um "trauma" a ser enfrentado de início. Lembro-me de um rapaz que procurou a secretária do Projeto para expor sua indignação dizendo que daquela maneira seria muito difícil para ele conseguir voltar a estudar. Dizia que por ter deixado a escola há muitos anos, desejava voltar exatamente para aprender e ao se deparar com a exigência de ter que provar conhecimentos escolares era, frequentemente, eliminado.

Esse fato nos levou a longas discussões, a entender a contradição que aquele rapaz havia expressado: como conseguir entrar em uma escola sendo que a exigência para o ingresso é já saber

\footnotetext{
${ }^{6}$ Os Centros de Estudos Supletivos (CES) foram implantados em todo país como modelo de educação de adultos tanto no aspecto de sua arquitetura funcional como no atendimento semipresencial. Para compreender a filosofia e sua proposta de organização ver Sérgio Mafra - Conhecendo um Centro de Estudo Supletivo. MEC, 1973.
} 
o que ainda seria ensinado? Após reflexões fundamentadas sobre o processo de exclusão a que se submete parcela representativa dessa população, decidiu-se pelo sorteio. Dessa forma, todos aqueles que procurassem o Projeto para dele participar estariam presentes em uma reunião ampla para a realização do sorteio das vagas existentes. A argumentação exposta era a de que todos tinham direito à educação e o problema estava na ausência de uma política pública de atendimento ao enorme contingente de brasileiros sem o ensino fundamental. Logo, rompíamos com a ideia de que “entrava quem sabia mais", para receber os sorteados e aí planejar um trabalho a partir da enturmação feita. O processo não deixou de produzir sentimentos de frustração, mas as pessoas podiam, ao menos, entender que não haviam sido excluídas por não apresentarem conhecimentos exigidos a priori e sim pela não oferta de escolas para a educação de adultos naquele momento.

Em 1996, o Projeto passou a se denominar Projeto de Ensino Fundamental - segundo segmento e, juntamente com o Projeto de Ensino Fundamental de Jovens e Adultos - primeiro segmento e o Projeto de Ensino Médio de Jovens e Adultos (PEMJA), formam o Programa de Educação Básica de Jovens e Adultos da UFMG (Proeja).

A passagem da expressão ensino supletivo para educação de jovens e adultos se deu com a promulgação da LDBEN 9.394/96, nos arts. 36 e 37, em que foram incorporados conceitos debatidos nas edições das Conferências Brasileiras de Educação. ${ }^{7}$ Essa mudança não foi meramente nominal, foi conceitual. A substituição do termo ensino, que está mais relacionado a atividades de instrução e de aprendizagem propriamente ditas, por educação introduziu uma compreensão mais alargada do fenômeno educativo. O conceito de educação é bem mais amplo, ele contempla as atividades de instrução e de aprendizagem indo além ao incorporar os processos de formação humana com suas múltiplas dimensões. Acrescente-se a essa reflexão os significados dos termos que se seguem ao tomar a expressão ensino supletivo como aquilo que será reposto nos termos da educação bancária (DI PIERRO, 2005) e educação de jovens e adultos em que se explicita e se dá ênfase aos sujeitos da ação educativa (HADDAD, 1997) e (PAIVA, 1997). Portanto, trata-se de um outro olhar sobre os processos de ensinar e de aprender dos jovens e adultos em vias de formação.

Os "novos" sujeitos da EJA são, mesmo contemporaneamente, ainda invisíveis nas estruturas e nas determinações das instituições de ensino superior. Mesmo não sendo uma parcela residual da população brasileira, pois há cerca de 65 milhões de brasileiros sem o ensino

\footnotetext{
${ }^{7}$ CBE (São Paulo, 1980), com o tema "Política educacional"; II CBE (Belo Horizonte, 1982), com o tema "Educação: perspectivas na democratização da sociedade"; III CBE (Niterói, 1984), com o tema "Das críticas às propostas de ação"; IV CBE (Goiânia, 1986), com o tema "Educação e Constituinte"; V CBE (Brasília, 1989), com o tema "Lei de Diretrizes e Bases da Educação Nacional: compromisso dos educadores"; e VI CBE (São Paulo, 1991)
} 
fundamental concluído (BRASIL, 2010), os cursos superiores reagem com lentidão as demandas de formação para esse público. Raras têm sido as IES que co-responsabilizam com a presença dessa população em meio às formulações de iniciativas de extensão, de ensino e de pesquisa.

Em 1996, realizou-se na UFMG o primeiro Seminário Universidade e Educação de Jovens e Adultos em comemoração aos dez anos do Projeto. Além de significar um balanço desde os anos de sua concepção, o Seminário foi um evento que congregou participantes de experiências de EJA de outras regiões do país como o Projeto Zé Peão ${ }^{8}$ da UFPB e o MOVA $^{9}$ da prefeitura de Porto Alegre. Sem uma política nacional de atendimento a educação de adultos, muitas eram as proposições em forma de projetos. Gestores de prefeituras e universidades passaram a ser pressionados para criar formas de atendimento aos trabalhadores dessas instituições. Tem-se nesse período das décadas de 1980 e 1990 o surgimento de projetos por todo território nacional como pode ser constatado nos ANAIS das edições do COLE, em que a socialização de experiências em EJA se deu no Seminário Educação de Jovens e Adultos Trabalhadores. como o de Olinda, Campinas, São Carlos, Ibirité, Angra dos Reis, Goiânia, São Paulo, Diadema, entre outros.

Na palestra de abertura do Seminário, ${ }^{10}$ Miguel Arroyo desenvolveu uma reflexão em que questionava a expressão ensino supletivo com tudo o que ela representava de concepção compensatória. Enfatizava que o atendimento a EJA não se tratava de "dar uma mamadeira" de conhecimentos aos jovens e adultos que não tinham podido frequentar a escola, fazendo referência ao ato de meramente depositar conteúdos na cabeça dos estudantes. Essa mesma crítica havia sido feita, décadas antes, por Paulo Freire (1974) ao se referir as práticas da educação compensatória que consideraram os educandos objetos depositários de matérias escolares pelos professores.

No Projeto em questão, os participantes não constituíam um público qualquer, pelo contrário, tratava-se de sujeitos socioculturais diferenciados, ou seja, eram jovens-adultos populares como sujeitos de direitos. Frente às suas especificidades exigia-se tratamento distinto no que se refere as dimensões formadoras dos respectivos ciclos de vida: trabalho, cultura, múltiplas linguagens, sexualidade e corporiedade. O mesmo era requerido no tocante ao desenho curricular, se eram outros sujeitos, logo, necessitavam de uma reorganização dos tempos e espaços e, ainda,

\footnotetext{
${ }^{8}$ Projeto Escola Zé Peão. Parceria entre a Universidade Federal da Paraíba e o Sindicato dos Trabalhadores da Construção Civil de João Pessoa. Palestra ministrada por Timothy Ireland no I Seminário Universidade e Educação de Jovens e Adultos, em 1996. DVD do acervo na Biblioteca Alaíde Lisboa, da Faculdade de Educação da UFMG.

${ }^{9}$ Movimento de Alfabetização de Adultos da Prefeitura de Porto Alegre. Palestra ministrada por Liana Borges no I Seminário Universidade e Educação de Jovens e Adultos, em 1996. DVD do acervo na Biblioteca Alaíde Lisboa, da Faculdade de Educação da UFMG.

10 Palestra ministrada por Miguel Arroyo no I Seminário Universidade e Educação de Jovens e Adultos, em 1996. DVD do acervo na Biblioteca Alaíde Lisboa, da Faculdade de Educação da UFMG.
} 
um esforço para incorporar ao tempo da escola, "outros tempos" de aprendizagem como o tempo do trabalho, o tempo do cinema, da diversão, do teatro e o tempo com a família. Na fala do Pró-Reitor à época, Tomás Aroldo da Mota Santos, ${ }^{11}$ “a sociedade precisava de utopias, utopias possíveis e necessárias".

Um momento singular do Seminário comemorativo aos dez anos do Projeto foi a participação do estudante egresso do Projeto, o técnico-administrativo João Romão, ${ }^{12}$ que fez uma avaliação dos seus primeiros anos. Segundo ele a importância da criação do Projeto foi fundamental já que "sem o qual funcionários e outros não teriam oportunidades de voltar as salas de aula".

João lembra que o início foi marcado por gestões junto a reitoria e a Secretaria Estadual da Educação para a garantia de sua continuidade.

Enfim, o projeto foi implantado. Passada a euforia da aula inaugural, não bastava apenas estudar, era preciso de forças, reivindicar. Garantindo a avaliação no final do curso, ou seja, ter autonomia para emitir seu próprio certificado, medida aliás, indispensável para a sobrevivência do Projeto.

À época, a proposta foi tida como ousada em relação ao que existia de educação de adultos ofertada pela Secretaria Estadual de Educação de Minas Gerais. Para que a Universidade pudesse avaliar e certificar os estudantes do ensino fundamental. foi necessário o reconhecimento e a autorização do Conselho Estadual de Educação para que ela procedesse a certificação. No período anterior a essa autorização, as primeiras turmas do Projeto tinham que se submeter à avaliações externas de desempenho nos exames supletivos ou nos centros de estudos supletivos para fins de certificação. João relata aquele período como um marco do momento seguinte em que o Projeto passaria a ter autonomia para elaborar uma proposta pedagógica própria.

Finalmente, em 1990, depois de várias conversas e Parecer da Secretaria de Estado e Educação, o sonho torna-se realidade. Forma-se a primeira turma originalmente do Projeto. CP/UFMG. A partir de então, fazia sentido o planejamento e a construção de uma nova metodologia de ensino.

Ao fim de sua fala, João Romão faz menção à expansão do atendimento, que inicialmente era para servidores da universidade e que, posteriormente, ampliou-se para a comunidade externa e enfatiza a dimensão formativa da participação social.

\footnotetext{
${ }^{11}$ Depoimento proferido por Tomás Aroldo da Mota Santos no I Seminário Universidade e Educação de Jovens e Adultos, em 1996. DVD do acervo da Biblioteca Alaíde Lisboa, da Faculdade de Educação da UFMG.

${ }^{12}$ Depoimento proferido por João Romão no I Seminário Universidade e Educação de Jovens e Adultos, em 1996. DVD do acervo da Biblioteca Alaíde Lisboa, da Faculdade de Educação da UFMG.
} 
Hoje, com 10 anos de existência, está consolidado o Projeto. Sua inserção social extrapola os muros da Universidade. O curso é fruto de um trabalho sério colocando o aluno como agente transformador de seu meio.

Naquele mesmo ano de 1996, duas apresentações abordando o Projeto da UFMG haviam sido socializadas no I Seminário Internacional Escolarização de Jovens e Adultos ${ }^{13}$ no Memorial da América Latina, em São Paulo. O intercâmbio dessas experiências culminou com o movimento de constituição dos fóruns de EJA por todo o país e da realização anual dos encontros nacionais de educação de jovens e adultos (SOARES, 2003).

Se na dimensão do direito à educação, o Projeto possibilitava o acesso de sujeitos que haviam interrompido sua escolarização, no aspecto da permanência restava primar pela qualidade da oferta a fim de avançar em direção a uma experiência significativa para aqueles que o demandavam. Um dos caminhos para se chegar à qualidade foi qualificar os professores que buscavam desenvolver no Projeto sua formação como graduandos dos cursos de licenciaturas.

Por isso, no mesmo ano em que havia sido criada a Habilitação em Educação de Adultos para os estudantes de Pedagogia, como discutiremos adiante, o Projeto de Extensão tomava como um de seus objetivos a formação dos licenciandos das demais áreas como Geografia, História, Ciências Biológicas, Matemática e Letras a partir da prática educativa com adultos. Para alcançar esse objetivo, o Projeto sempre dedicou algumas horas por semana para reuniões de discussões e análise da prática pedagógica. São três as reuniões ${ }^{14}$ que compõem a dimensão da formação: a primeira chamada de reunião de área, como o nome já diz, reúne semanalmente os estudantes de uma mesma área, sob a coordenação de um professor da Universidade; a segunda, chamada de reunião de equipe, reúne também semanalmente, os monitores das áreas que dão aula para uma mesma turma, considerados professores em formação. A terceira é a reunião geral que se realiza uma vez por mês entre todos os envolvidos no Projeto incluindo um representante dos estudantes de cada sala.

\footnotetext{
${ }^{13} \mathrm{O}$ primeiro trabalho apresentado foi de autoria de Júlio Emílio Pereira et al, intitulado Reflexão na Ação: uma experiência de ensino de ciências para jovens e adultos trabalhadores no projeto supletivo CP/UFMG. O segundo trabalho foi de autoria de Maria da Conceição Ferreira Reis Fonseca sob o título A educação matemática na educação de jovens e adultos - uma experiência de elaboração de proposta para o trabalho a ser desenvolvido no projeto supletivo do Centro Pedagógico, UFMG. Ver Anais do Seminário Internacional Educação e Escolarização de Jovens e Adultos. Memorial da América Latina. Maio/1996

${ }^{14}$ Para entendimento da proposta curricular ver: COELHO, A.M.S.; FONSECA, M.C.F.R.; DINIZ-PEREIRA, J. E.; SOARES, L.J.G. A elaboração da proposta curricular como processo de formação docente. Alfabetização $e$ Cidadania Revista de Educação de Jovens e Adultos. São Paulo, v.1, n.11, p.75-85, 2001.
} 
A propósito da reunião de equipe, acompanhei semanalmente, durante o segundo semestre de 1992, um grupo de licenciandos que discutiu sobre quem eram os sujeitos da turma em questão, quais os motivos que os levaram a interromper os estudos, quais as motivações e as expectativas que os fizeram retornar aos estudos. Refletíamos sobre as práticas dos monitores, suas angústias e possibilidades. Ao final daquele semestre, escrevemos coletivamente um relato analisando a riqueza daquela experiência vivenciada que foi publicado na Educação em Revista. (SOARES et al, 1993/1994).

\section{A FORMAÇÃO INICIAL NOS CURSOS DE GRADUAÇÃO}

A formação específica de docentes para atuar na EJA vem, historicamente, sendo discutida desde meados do século XX. Encontramos, em congressos e eventos, afirmações que diziam da necessidade de se ter uma preparação para o professor e a professora que fosse atuar com jovens e adultos em processo de escolarização, como consta, por exemplo, nos Anais do I e do II Congresso Nacional de Educação de Adultos, realizados no Rio de Janeiro em 1947 e 1958 respectivamente.

Nas décadas seguintes, principalmente após o estabelecimento do direito de todos à educação expresso na Constituição Federal de 1988, iniciativas de atendimento ao público jovem e adulto, que passaram a ser desenvolvidas por estados e municípios, foram acompanhadas por atividades de formação em serviço de professores. Ferreira (2016) analisa o caso de Betim MG em que os professores relatam as atividades realizadas e avaliam aquele período como sendo de reconhecimento e valorização profissional.

Mais recentemente, estudos e pesquisas (HADDAD, 2007, DI PIERRO, 2005, RIBEIRO,1999; PAIVA, 2006; MACHADO, 2010; VÓVIO, 2010) têm enfatizado a necessidade de se ter, principalmente na formação inicial ofertada pelas universidades, uma preparação que corresponda às realidades e necessidades dessa população. Nesse sentido, a profissionalização do educador de jovens e adultos tem se tornado cada vez mais nuclear, tanto nas práticas educativas como nos fóruns de debates.

Atualmente, de modo geral, a educação de jovens e adultos está presente nos cursos de Pedagogia $^{15}$ por meio ora de disciplinas optativas, ora de disciplinas obrigatórias, pelo acompanhamento de estágios supervisionados no campo, pela realização de TCCs e em Projetos de Extensão. Ainda é rara a presença de estudos, discussão e debates sobre a EJA nos cursos de

\footnotetext{
${ }^{15}$ A UNEB de Juazeiro foi a primeira instituição de ensino superior a criar em 1985 uma habilitação em educação de adultos no Curso de Pedagogia.
} 
licenciatura em Matemática, Língua Portuguesa, História, Geografia, Ciências Biológicas e Educação Física. Nesse sentido, podemos afirmar que a formação de professores para atuarem nessa área ainda caminha a passos lentos.

Essa situação era ainda mais crítica em meados dos anos 1980, quando eram raras as iniciativas de formação inicial voltadas para a EJA. Desde 1986, houve na Faculdade de Educação, da UFMG, a inclusão da habilitação em Educação de Adultos no currículo do curso de Pedagogia. Desde aquele período, os estudantes de Pedagogia podem optar em direcionar sua formação na preparação para serem futuros profissionais na educação de adultos ou seja, "atuar como professores das séries iniciais do ensino fundamental, como coordenadores de cursos noturnos ou de diferentes projetos no campo da Educação Popular, bem como na atividade de assessoria" (GIOVANETTI, 2000, p. 200).

Algumas ONGs e mesmo grupos de EJA no interior das universidades eram contatados para prestarem assessorias nessas atividades de formação. Em 1996, respondendo a uma demanda da Secretaria Estadual de Educação de Minas Gerais, o "Grupo de Educação de Jovens e Adultos da UFMG coordenou seminários de formação de professores do ensino regular de suplência, que atingiram aproximadamente 500 professores" (GIOVANETTI, 2000, p. 201). A solicitação dos seminários se deu pela necessidade de se discutir a relação entre teoria e prática, uma vez que os professores não haviam tido nenhuma atividade formativa desde quando ingressaram para trabalhar com o público jovem e adulto. Essa atividade, somada ao vínculo com o Projeto de Extensão e a atuação no Curso de Pedagogia resultaram na criação do Núcleo de Educação de Jovens e Adultos.

No início, ao optar pela Habilitação em Educação de Adultos, o(a)s aluna(o)s cursavam disciplinas cujas temáticas abordavam a fundamentação teórica, a metodologia, a didática e o estágio supervisionado com jovens e adultos. É desse período as discussões de questões como: quem era o público jovem e adulto que demandava a EJA? Qual era a realidade vivida por essa população e que expectativas apresentava como motivações para voltarem a estudar? Quem era o educador da EJA e como se preparavam para atuar no campo? Quais as políticas públicas existentes que garantiam a oferta da EJA?

Em 2003, realizei uma investigação com egressos do curso de Pedagogia da UFMG com habilitação nessa área. A pesquisa procurou analisar a pertinência da profissionalização desse educador, o significado da formação inicial em EJA para os egressos e para os professores da habilitação e a inserção dos egressos no campo de trabalho (SOARES, SIMÕES, 2004). Interessava-nos saber se havia ou não a necessidade de uma preparação diferenciada de professores para atuarem na EJA. Foi realizado um levantamento do universo dos egressos do curso desde a sua 
criação, em 1986, até 2002. Enviamos um questionários aos ex-estudantes e, posteriormente, selecionamos uma amostra para ser entrevistada. Do total de participantes da pesquisa, 30\% não trabalhavam na área de educação, 50\% estavam em outros espaços educativos e apenas $20 \%$ dos egressos atuavam em frentes afins com a EJA.

A pesquisa apontou que há, sim, a necessidade de uma preparação diferenciada para os professores que irão atuar na EJA. Essa afirmação baseia-se na constatação, identificada nas respostas aos questionários e às entrevistas, do despreparo do profissional para lidar com questões distintas do ensino fundamental - ou do dito "ensino regular". Os egressos citaram, ainda, a importância de uma discussão mais ampliada do conceito de educação levando em conta as características dos sujeitos atendidos. Ao serem questionados sobre os recursos didáticos utilizados no trabalho com jovens e adultos, assinalaram, também, a inadequação curricular quando se pensa na prática com esse público. Perguntados sobre as razões pelas quais não atuavam na EJA, afirmaram que não haviam conseguido emprego na área. Na rede pública, apontaram, como principal motivo para que isso ocorresse, a ausência de concurso específico para a EJA. Na rede particular, indicaram que as escolas tendem a aproveitar os professores que nela já trabalham. Outros disseram ter se deparado com uma visão negativa, uma desvalorização, do campo de trabalho voltado para esse público, que se vale, em muitos casos, do trabalho voluntariado.

É de se surpreender que, passados mais de dez anos da conclusão da pesquisa, deparamo-nos com perguntas, por parte dos atuais estudantes de Pedagogia, no momento em que fazem sua opção pela formação complementar em EJA, que nos levam à reflexão sobre os mesmos tipos de problemas apontados pelos egressos: indagam, por exemplo, se a EJA vai acabar ou se haverá concurso público para trabalharem na área.

Uma crítica recorrente dos egressos sobre a lacuna na formação no que se refere à preparação para alfabetizar adultos levou-nos, posteriormente, em 2003, a introduzir no currículo do curso de Pedagogia a disciplina Alfabetização e Letramento para EJA.

Com a aprovação em 2005, pelo Conselho Nacional de Educação, das Diretrizes Curriculares Nacionais para o Curso de Pedagogia, constata-se uma redução da oferta da habilitação em EJA nas universidades. Entre as instituições que deixaram de ofertar, em formato de habilitação para EJA, está a própria UNEB de Juazeiro, na Bahia e a UNIJUÍ do Rio Grande do Sul. Diversos motivos podem ser apontados para explicar esse decréscimo. Primeiramente, por constar nas Diretrizes que o aprofundamento em alguma modalidade de ensino não configuraria, de forma alguma, uma habilitação, na medida em que objetivo do Curso de Pedagogia deveria ser a formação de professores para exercer funções de magistério na Educação Infantil e nos anos iniciais do 
Ensino Fundamental. Essa orientação fez com que alguns dos poucos cursos existentes deixassem de ofertar uma habilitação específica para a EJA.

Em um grupo de universidades, que tomaram como base a organização do Curso de Pedagogia proposta nas Diretrizes, que se prevê um núcleo de aprofundamento e diversificação de estudos, os currículos foram reestruturados, justificando-se a opção pela formação em EJA com base nas áreas de atuação profissional priorizadas pelos projetos pedagógicos de suas instituições. Dessa maneira, mantiveram a preparação de pedagogos para atuarem na EJA, a UFPB, a UERJ e a UFMG. No caminho oposto ao fechamento da habilitação impulsionado pelas novas Diretrizes, a UFRJ deu início, em 2005, à preparação específica do profissional para atuar na EJA.

Na UFMG, a reforma curricular transformou a Habilitação em Formação Complementar para a EJA, com a oferta de cinco disciplinas a serem cursadas a partir do sexto período, quais sejam:

Tabela das Disciplinas ofertadas para a Formação Complementar em Educação de Jovens e Adultos

\begin{tabular}{|c|l|c|}
\hline Período & \multicolumn{1}{|c|}{ Disciplinas } & Carga horária \\
\hline $7^{\circ}$ & Políticas Públicas, Movimentos Sociais e Cidadania & $60 \mathrm{hs}$ \\
\hline $8^{\circ}$ & Fundamentos Teórico-metodológicos da Educação Popular & $60 \mathrm{hs}$ \\
\hline $9^{\mathbf{o}}$ & Organização da Educação de Jovens e Adultos & $60 \mathrm{hs}$ \\
\hline $9^{\circ}$ & Metodologia da Alfabetização de Jovens e Adultos & $60 \mathrm{hs}$ \\
\hline $9^{\circ}$ & Prática em Educação de Jovens e Adultos & $60 \mathrm{hs}$ \\
\hline
\end{tabular}

Fonte: Colegiado do Curso de Pedagogia da Faculdade de Educação da UFMG - 2016

No momento, estou orientando um trabalho de mestrado que está dando continuidade à pesquisa anterior com os egressos do Curso de Pedagogia da UFMG concluintes no período entre 2003 e $2013 .^{16}$

\section{A PESQUISA E A FORMAÇÃo CONTINUADA NA PÓS-GRADUAÇÃo}

Como um dos objetivos do Projeto de Ensino Fundamental de Jovens e Adultos segundo segmento, foi, e ainda é, a realização de pesquisas no campo da educação de adultos, muitos monitores, ou seja, professores-em-formação, despertaram para pesquisar questões que emergiram da experiência no Projeto em suas monografias de conclusão de curso, dissertações de mestrado e teses de doutorado, em tornar a experiência e seus sujeitos, em diferentes aspectos, objetos de investigação. Com a comemoração dos 30 anos de sua criação, está sendo realizado um levantamento quantitativo e qualitativo das temáticas que foram apreciadas ao longo desses anos.

\footnotetext{
${ }^{16}$ Pesquisa em andamento, no PPGE/UFMG, da mestranda Rafaela Carla e Silva Soares sob o título: O educador de jovens e adultos e sua formação inicial em um curso de Pedagogia.
} 
Até o momento foram localizados 4 trabalhos de conclusão de curso, quinze artigos, onze dissertações de mestrado e três teses de doutorado.

Assim como outros colegas do Programa de Pós-graduação em Educação da UFMG, tive a oportunidade de orientar algumas pesquisas que resultaram em dissertações de mestrado. A primeira delas, intitulada "Educação ainda que tardia: a exclusão da escola e a reinserção de adultos das camadas populares em um programa de EJA" colocava como central a seguinte problemática:

“será que a conquista do direito à educação pelos alunos em questão representa - tal como a luta dos inconfidentes, na qual os sujeitos se inspiraram para verbalizar essa conquista - uma face da luta que empreendem, cotidianamente, em favor da realização da cidadania, mesmo que parcial e tardia?" (SANTOS, 2003).

Em seguida, orientei a pesquisa "Trajetórias de educadores construídas na Educação de Jovens e Adultos: experiências e significados", defendida em 2008, que se apropriou dos cadernos de campo utilizados pelos monitores da área de história como ferramentas auxiliares no processo de formação do educador de jovens e adultos. ${ }^{17} \mathrm{~A}$ terceira, intitulada "Entre desejos, desafios e direitos: a EJA como espaço de ampliação da qualidade de vida da terceira idade", procurou discutir quais as expectativas expressas por sujeitos considerados idosos ao buscarem a educação de jovens e adultos. (COURA, SOARES, 2011).

Atualmente, oriento nova pesquisa de Mestrado que busca saber até que ponto os estudantes que passam pelo Projeto incorporam a noção de cidadania ao freqüentarem espaços urbanos da cidade. $^{18}$

O Programa de Educação Básica de Jovens e Adultos da UFMG tem como uma de suas funções prioritárias contribuir com a formação do educador da EJA. Por meio da atuação nos três projetos existentes, os estudantes das diversas licenciaturas iniciam um processo de docência acompanhado com discussões sistemáticas sobre a própria prática em sala de aula. ${ }^{19}$

Com a quase inexistência de formação inicial nos cursos de licenciatura para atuar na EJA, muitos professores da educação básica das redes públicas e privadas recorrem a pós-graduação no intuito de prosseguirem sua formação aprofundando seus conhecimentos e realizando pesquisas no

\footnotetext{
${ }^{17}$ Emmeline Salume Mati. Trajetórias de educadores construídas na Educação de Jovens e Adultos: experiências e significados. Dissertação (Mestrado em Educação) - Universidade Federal de Minas Gerais, 2008.

${ }^{18}$ Pesquisa em andamento, no PPGE/UFMG, da mestranda Suellen Guimarães Alves sob o título: “O educando da eja e a cidade: a reinserção no contexto escolar e a possibilidade de vivenciar novas práticas espaciais".

${ }^{19}$ Para um aprofundamento sobre a formação no Projeto ver: DINIZ-PEREIRA, J.E.; FONSECA, M.C.F.R. Identidade docente e formação de Educadores de Jovens e Adultos. Educação e Realidade. Porto Alegre, v. 26, n. 2, p. 51-73, 2001 .
} 
campo da educação de jovens e adultos. Anualmente, temos recebido no Programa de PósGraduação em Educação da UFMG um número significativo de professores das mais diversas regiões do país que se candidatam a realizar o mestrado ou o doutorado nas treze linhas ofertadas pelo programa. $\mathrm{O}$ interesse específico pela área de EJA pelos mestrandos e doutorandos certamente expressa a consolidação da área em uma universidade que vem mantendo um conjunto de ações a ela relativo há três décadas. Ao mesmo tempo, a busca pela formação em nível de pós-graduação pode ser considerada uma tendência mais ampla, observada em todo o País.

Podemos constatar um crescimento do número de pesquisas que se dedicam ao tema (SOARES, 2011). No GT de EJA da Associação Nacional de Pesquisa e Pós-Graduação em Educação (ANPEd), é frequente a apresentação de pesquisas que tem tomado como objeto de estudo os processos de formação nos distintos projetos e programas de EJA existentes como Programa Brasil Alfabetizado, Projovem, Proeja, entre outros.

Com a criação do Programa Nacional de Integração da Educação Profissional com a Educação Básica na Modalidade de Educação de Jovens e Adultos, Proeja em 2006, o Ministério da Educação incentivou, por meio de editais, a oferta de cursos de especialização em EJA nas Instituições Federais de Educação Superior com o intuito de formar docentes para atuar na área.

No ano seguinte, a Resolução 01, de 8 de junho de 2007, estabeleceu normas para o funcionamento de cursos de pós-graduação lato sensu, em nível de especialização. Existe hoje um número considerável de ofertas desses cursos de iniciativas tanto de instituições públicas como privadas de ensino superior. $^{20}$

A respeito da formação continuada, a recente Resolução 02 , de $1^{\circ}$ de julho de 2015 , do Conselho Nacional de Educação, estabelece no art. 16 que

\footnotetext{
a formação continuada compreende dimensões coletivas, organizacionais e profissionais, bem como o repensar do processo pedagógico, dos saberes e valores, e envolve atividades de extensão, grupos de estudos, reuniões pedagógicas, cursos, programas e ações para além da formação mínima exigida ao exercício do magistério na educação básica, tendo como principal finalidade a reflexão sobre a prática educacional e a busca de aperfeiçoamento técnico, pedagógico, ético e político do profissional docente.
}

\footnotetext{
${ }^{20}$ A título de ilustração foi criado como um Mestrado Profissional na UNEB, o Programa de Pós-Graduação em Educação de Jovens e Adultos. Trata-se de uma iniciativa para atender exclusivamente aos interessados em realizar um mestrado voltado às questões do público jovem e adulto.
} 
Com base nessa Resolução, estamos vivendo processos de reformas curriculares nos cursos de formação de professores o que pode significar um momento promissor para a incorporação de práticas de EJA na Pedagogia e nas Licenciaturas superando suas ausências.

\section{CONSIDERAÇÕES FINAIS}

Durante a realização do III Seminário Universidade e Educação de Jovens e Adultos: 30 anos de EJA na UFMG, em maio último, uma pergunta pairou no ar: teria sentido a universidade manter em seu interior uma iniciativa de curso para jovens e adultos nos dias atuais? As respostas a essa questão podem ser encontradas nas falas dos distintos atores, nas mesas-redondas dos cinco dias do seminário. O fato de ser um dos projetos de extensão mais antigos da universidade e de receber o maior número de bolsas 56 em 2016, diz da importância e do compromisso da instituição com a problemática da educação de jovens e adultos no país.

Os depoimentos dos estudantes egressos expressam os sentidos e os significados atribuídos as suas participações ao longo dos anos ao se referir ao aspecto do acolhimento na medida em que tinham ficado muitos anos sem frequentar uma escola, o que lhes impunham um sentimento de vergonha frente aos que estudavam. Fazem referência também ao ambiente dito por muitos como 'familiar' em que ao serem recebidos passam a fazer parte dos que já estavam, elevando com isso a autoestima de voltar a ser estudante. Há os que também afirmaram que ter participado do Projeto foi mais profundo que só estudar. Contam dos efeitos sobre a vida familiar, na relação com os filhos estudantes e sobre a vida profissional, enfatizando a consciência de trabalhador em uma sociedade de classes.

Para os que tiveram sua formação como professores no Projeto foram acentuados os aspectos da identificação e a sensibilidade pedagógica com os sujeitos bem como os vínculos estabelecidos com esse público no trabalho com jovens e adultos populares. Ressaltaram o quanto essa experiência deixou marcas positivas em suas características como docentes, seja da educação básica ou do ensino superior.

Ante a dramaticidade das histórias de vida dos jovens-adultos populares é possível reconhecer nas ações e nas práticas do Programa de Educação Básica de Jovens e Adultos a função social da universidade no que Freire (2005) considerou como a busca pela humanidade roubada de parcela significativa da população brasileira. 


\section{REFERÊNCIAS}

BEISIEGEL, C. A política de educação de jovens e adultos analfabetos no Brasil. In: ANDRADE, D. (Org.). Gestão democrática da educação: desafios contemporâneos. Petrópolis, RJ: Vozes, 1997.

BRASIL. CNE/CP. Resolução 02/2015. Define as Diretrizes Curriculares Nacionais para a formação inicial em nível superior (cursos de licenciatura, cursos de formação pedagógica para graduados e cursos de segunda licenciatura) e para a formação continuada. Diário Oficial da União, Brasília, 2 jul. 2015 - Seção 1, p. 8-12.

COURA, I; SOARES, L. Entre desejos, desafios e direitos: a EJA como espaço de ampliação da qualidade de vida da terceira idade. In: SILVA, I.; LEÃO, G. (Orgs.). Educação e seus atores: experiências, sentidos e identidades. Belo Horizonte: Autêntica Editora, 2011. p. 27-59.

DI PIERRO, M. C. Notas sobre a redefinição da identidade e das políticas públicas de Educação de Jovens e Adultos no Brasil. Educ. Soc., Campinas, vol. 26, n. 92 (Especial), p. 1115-1139, out. 2005.

FERREIRA, A.R.C. A Educação de Pessoas Jovens e Adultas em Betim (MG), 1988-2007: perspectivas de educadores e professores de matemática. 2016. Tese (Doutorado) - Faculdade de Educação, Universidade Federal de Minas Gerais.

FONSECA, M.C.F.R. Lembranças da Matemática Escolar: a constituição dos alunos da EJA como sujeitos da Aprendizagem. Educação e Pesquisa. São Paulo: USP, v. 27, n. 2, p. 339-354, 2001.

FREIRE, P. Pedagogia do Oprimido. Rio de Janeiro, Paz e Terra, 2005.

GIOVANETTI, M.A.G. Núcleo de Educação de Jovens e Adultos: pesquisa e formação - NEJA/UFMG Tendências e perspectivas do conhecimento no campo da EJA. Dossiê: Educação de Jovens e Adultos. Educação em Revista, Belo Horizonte: FaE/UFMG, n. 47, dez.2000.

HADDAD, S. Novos Caminhos em Educação de Jovens e Adultos. Global Editora, 2007.

. A educação de jovens e adultos e a nova LDB. In: BRZEZINSKI, Iria. (Org.). LDB Interpretada: diversos olhares. São Paulo: Cortez Editora, 1997.

MACHADO, M. M. Processos de formação de educadores de jovens e adultos - os desafios políticos e pedagógicos na formação de educadores de EJA no Brasil. In: SOARES, Leôncio. (Org.). Convergências e tensões no campo da formação e do trabalho docente. Belo Horizonte, MG: Autêntica, 2010. p. 100-121.

PAIVA, J. Concepções e movimentos pela formação de pedagogos para a Educação de Jovens e Adultos na Faculdade de Educação da Universidade do Estado do Rio de Janeiro. In: Formação de educadores de jovens e adultos. Belo Horizonte: Autêntica/Secad-MEC/Unesco, 2006.

Desafios à LDB: educação de jovens e adultos para um novo século?. In: ALVES, Nilda; VILLARDI, Raquel. (Org.). Múltiplas Leituras da Nova LDB. Rio de Janeiro: Qualitymark; Dunya, 1997.

RIBEIRO, V. M.. A formação de educadores e a constituição da educação de jovens e adultos como campo pedagógico. Educação e Sociedade, Campinas, SP, v. 20, n.69, p. 184-201, 1999.

SANTOS, G. Educação ainda que tardia: a exclusão da escola e a reinserção de adultos das camadas populares em um programa de EJA. Revista Brasileira de Educação, no. 24, set/ou/nov/dez, p. 107-125, 2003.

SOARES, L (Org). Educação de Jovens e Adultos. O que revelam as pesquisas. Belo Horizonte: Autêntica Editoram 2011. (Col. Estudos em EJA, 11)

et al. A vida do aluno-trabalhador orientando a prática pedagógica em uma proposta de educação de jovens e adultos. Educação em Revista. Belo Horizonte, n. 18/19, p. 116-119, dez. 1993; jun. 1994.

SOARES, L. O Direito à Educação. Cadernos Ensinar. Centro Pedagógico. Escola de Ensino Fundamental da UFMG. Belo Horizonte, no. 3, p. 71-76, jun 1997.

Os fóruns de Educação de Jovens e Adultos: articular, socializar e intervir. Presença Pedagógica. Belo Horizonte-, v. 9, n.54, p. 15-21, 2003.

; SIMÕES, F. A formação inicial do educador de jovens e adultos. Educação \& Realidade. Porto Alegre: UFRS, v. 29, n. 2, jul./dez. 2004.

SOARES, L; GALVÃO, A. M. O. Uma história da alfabetização de adultos no Brasil. In: STEPHANOU, Maria; BASTOS, Maria Helena. (Orgs.). Histórias e memórias da educação no Brasil. Petrópolis: Vozes, 2005. p. $257-277$. 
VÓVIO, C. L.. Formação de educadores de jovens e adultos: a apropriação de saberes e de práticas conectadas a docência. In: DALBEN, Ângela; DINIZ, Júlio; LEAL, Leiva; SANTOS, Lucíola. (Org.). Convergências e tensões no campo da formação do trabalho docente. Belo Horizonte: Autêntica Editora, 2010. p. 60-77.

\section{RESUMO}

Este artigo descreve e analisa um conjunto de ações que, desde a década de 1980, passou a ser desenvolvido na Faculdade de Educação da Universidade Federal de Minas Gerais, envolvendo simultaneamente a extensão, a formação e a pesquisa voltadas para a educação de jovens e adultos. Destaca-se a criação de um Curso Supletivo para atender inicialmente os funcionários que trabalhavam na Universidade. Além disso, foi criada a habilitação em educação de adultos no Curso de Pedagogia e iniciou-se uma linha de pesquisa no Programa de Pós-graduação. Ao longo desses 30 anos foram muitos os estudantes das diversas licenciaturas que tiveram no Projeto de Extensão a iniciação à educação e, em especial, à educação de adultos. Entre eles, encontramos alguns que deram prosseguimento à profissão docente, ingressando nas redes públicas e privada de ensino bem como no ensino superior. Encontramos também um grupo significativo de egressos que optou por realizar pesquisas cujas temáticas surgiram da própria prática com os jovens e adultos do Projeto. Somam-se a esses, os estudantes de Pedagogia que escolheram a formação específica, por meio da habilitação em EJA, para trabalhar com jovens e adultos.

Palavras-chave: Educação de Jovens e Adultos, práticas, pesquisas e formação

\section{YEARS OF YAE IN UFMG- OUTREACH, FORMATION, AND RESEARCH}

\section{ABSTRACT}

This article describes and analyzes a set of actions that has been developed in the Education School of Universidade Federal de Minas Gerais involving simultaneously outreach programs, formation, and research on Young and Adult Education (YAE), since the 1980s. We highlight the creation of an Equivalency Courseto initially attend University workers. Besides this, an habilitation on adult education was created in the Pedagogy major, as well as a line of research on the graduate program. During these 30 years, many students from different teaching degrees started their career as educators, especially in YAE, in this outreach program. Amongst them, some continued as teachers in private and public schools and universities. We also find a significant group of previous graduates who researched themes which arose from their own practice with youngsters and adults from the project. Moreover, there were Pedagogy students who chose to work with youngsters and adults, through the YAEthe specific formation.

Key words: Young and Adult Education; practices; researches; formation.

Submetido em Jan. 2016 Aprovado em Jun. 2016 